system to direct electronic transfers. All of this is useful and not easily accessible information. A 46-page long bibliography lists predominantly United States books, articles and documents about the legal issues of electronic fund transfers systems.

The Computer/Law Journal is published quarterly by the Center for Computer/Law, 530 West Sixth Street, Los Angeles, California 90014, U.S.A. Annual subscription is U.S. \$54 (U.S. \$58 outside the United States). Single issues are priced at U.S. $\$ 16$ (U.S. $\$ 17$ outside the United States).

\title{
NEW BIBLIOGRAPHIES
}

Interesting, if not always satisfactorily comprehensive, bibliographies on different subjects related to international law are published by Gale Research Company within its International Relations Information Guide series. The two most recent volumes in the series (Volume 8 and 9 respectively) contain useful information for researchers not only in the United States, but also in other countries.

The International Relations of Eastern Europe: $A$ Guide to Information Sources. Edited by Robin Alison Remington. Detroit, Michigan: Gale Research Company, 1978. Pp. xvi, 273. U.S. $\$ 22.00$.

This work, Volume 8 in the series, is a comprehensive bibliography of books, articles and other writings pertaining to Eastern Europe. It is divided into two major sections. The first, "Eastern Europe as a Region," is divided into chapters such as "Comparative Approach," "Historical Approach," and "The Warsaw Treaty Organization (WTO)." The second, "County-Specific Sources," identifies and describes sources relating to Albania, Bulgaria, Czechoslovakia, East Germany, Hungary, Poland, Rumania, and Yugoslavia. Many of the entries are annotated or accompanied by explanatory abstracts.

The European Communities; $A$ Guide to Information Sources. By J. Bryan Collester. Detroit, Michigan: Gale Research Company, 1979. Pp. xxxii, 265. U.S. \$22.00.

This annotated and categorized bibliography, representing Volume 9 in the series, lists some 1400 books, pamphlets, and dissertations principally concerned with the political aspects of European integration. The introduction is in the form of a bibliographical note examining the most significant sources of literature in each of the substantive chapters of the bibliography: theoretical and conceptual studies of integration; general, historical, and institutional studies of integration; background and policy 